\title{
Updated Candidate List for Engineered Barrier Materials
}

\section{RECEIVED}

R. D. McCright

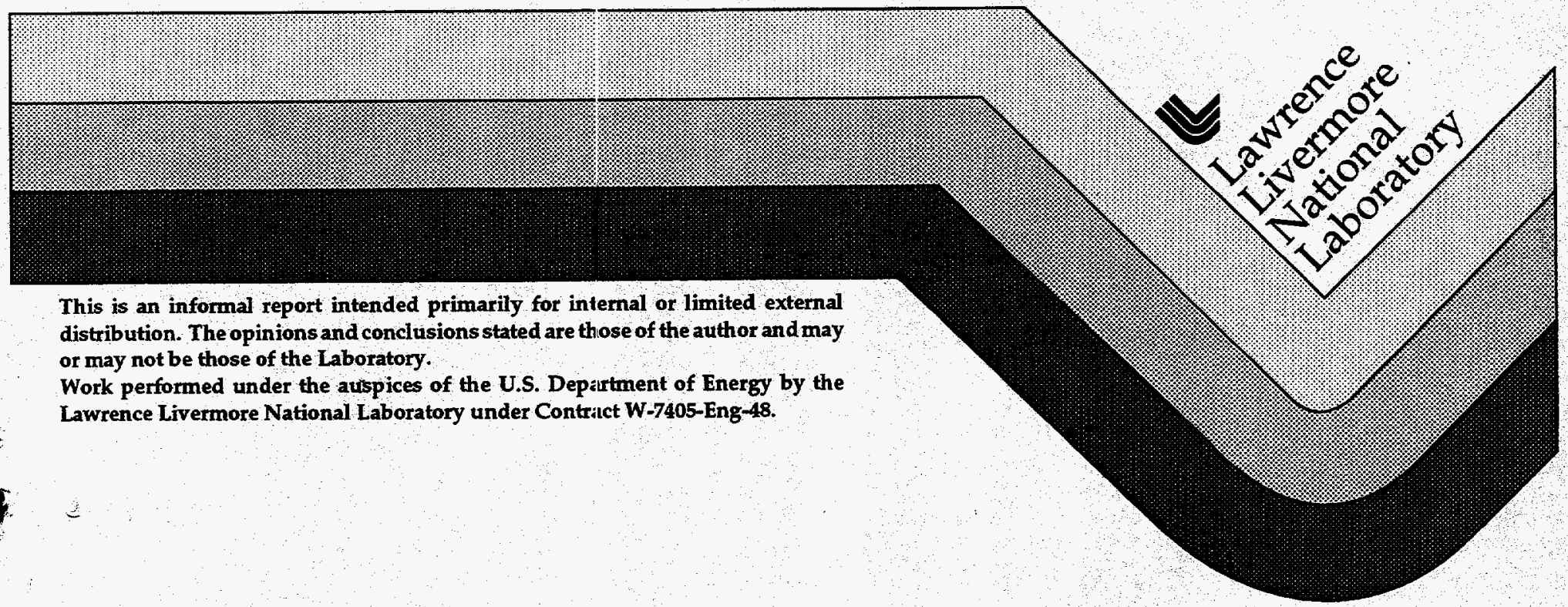


This document was prepared as an account of work sponsored by an agency of the United States Government. Neither the United States Government nor the University of California nor any of their employees, makes any warranty, express or implied, or assumes any legal liability or responsibility for the accuracy, completeness, or usefulness of any information, apparatus, product, or process disclosed, or represents that its use would not infringe privately owned rights. Reference herein to any specific commercial products, process, or service by trade name, trademark, manufacturer, or otherwise, does not necessarily constitute or imply its endorsement, recommendation, or favoring by the United States Government or the University of California. The views and opinions of authors expressed herein do not necessarily state or reflect those of the United States Government or the University of California, and shall not be used for ads advertising or product endorsement purposes.

This report has been reproduced directly from the best available copy.

Available to DOE and DOE contractors from the Office of Scientific and Technical Information

P.O. Box 62, Oak Ridge, TN 37831

Prices available from (615) 576-8401

Available to the public from the National Technical Information Service

U.S. Department of Commerce 5285 Port Royal Road Springfield, VA 22161

Prepared by Yucca Mountain Site Characterization Project (YMP) participants as part of the Civilian Radioactive Waste Management Program. The YMP is managed by the Yucca Mountain Site Characterization Project Office of the U.S. Department of Energy, Las Vegas, Nevada. 


\section{DISCLAIMER}

Portions of this document may be illegible in electronic irnage products. Images are produced from the best available original document. 


\title{
Updated Candidate List for Engineered Barrier Materials
}

\author{
R. D. McCright
}

This report presents a list and discussion of candidate materials to be evaluated over the next several years during advanced design phases for the waste package used for the disposal of spent nuclear fuel and high-level vitrified nuclear waste. The discussion of candidate materials is organized by the formal Yucca Mountain Project (YMP) Work Breakdown Structure (WBS), which corresponds to different components of the waste package and engineered barrier system. By far, the greatest effort has gone into the candidate material list for the metallic barriers, because of the much greater emphasis on designs for metal containers and longer project history in testing and evaluating metals. This report was originally prepared in September 1994 as a project deliverable (MOL 01). Since that time, there have been some project developments that result in some minor changes and additional discussion, which are presented in this report.

A discussion of the descriptions and functions of the various components of the engineered barrier system (EBS) is available in the Controlled Assumptions Document for the repository and waste package design [1]. Because design is an evolving process, reconsiderations in the role, of the various components of the EBS are occurring. These reconsiderations are noted below. The following engineered barrier components are discussed in this report:

(1) The metallic barriers comprise the waste package container. Current waste package designs focus on a multiple barrier disposal container of at least two materials. The primary function of the waste package container is to provide the containment of the waste. There are two generic types of waste packages, one for spent fuel and the other for reprocessed waste that is supplied in a vitreous form. Most spent fuel is expected to arrive at the repository inside a multi-purpose container (MPC) that was previously used for interim storage and transportation. Different sizes of MPCs are expected, depending on the availability of transportation modes to individual reactor sites. At the repository surface facility, the MPCs will be enclosed in the multiple barrier disposal waste package. Some spent fuel will not arrive in MPCs, but will be encanistered in the disposal package at the repository facilities. Similarly, reprocessed waste will arrive at the repository site in pour canisters. Current plans are to place four pour canisters into a single waste package container. As will be explained later, the choices of materials for multiple barrier waste packages have been influenced by previous work on the Site Characterization Plan - Conceptual Design (SCP-CD). In the SCP-CD a single metal barrier, comprised of a corrosion resistant metal to be emplaced in a borehole, was proposed. The corrosion resistant materials evaluated for the SCP-CD served as a starting point for advanced designs.

(2) The "basket" material is the partitioning material used to separate spent nuclear fuel assemblies and whose primary purpose is to prevent a criticality event. In most cases, the basket will fit inside the multi-purpose canister planned for storage and transportation of the spent fuel from reactor sites to an interim storage facility and eventually to the disposal site. Because large spent fuel waste packages are currently being emphasized, the importance of criticality control materials is receiving much greater attention than in previous Yucca Mountain waste package designs, such as those associated with the SCP-CD involving only a few spent fuel assemblies per container. The basket partitions also provides the major conduit for heat transfer from the spent fuel to the exterior environment, since it is plarmed to fill the waste package with an inert gas. Waste packages for vitrified waste (a borosilicate glass) do not have any need for a basket material.

(3) The filler material, which would be used inside spent nuclear fuel waste packages, would provide an additional barrier for controlled release and provide some control of criticality. Filler materials are not currently planned to be used in waste packages, but remain an option in case materials proposed for other engineered barrier components cannot be demonstrated to adequately fulfill these functions.

(4) The packing material, which would be used outside the waste package (both spent fuel and glass), provides a medium for controlling the near waste package environment. By judicious choice of the material (or combinations of materials), packing limits water contact with the container surface and provides $\mathrm{pH}$ buffering and redox buffering to mitigate corrosion of the container. Packing would affect the temperatures on the waste package

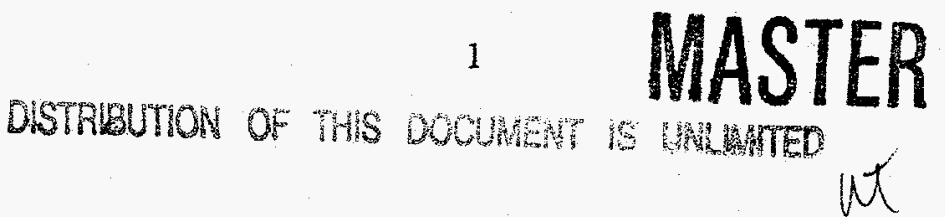


surface, since most proposed materials are poor thermal conductors. Additionally, appropriate choice of the packing material can retard release of radionuclides from a breached container. Historically, packing materials were not widely considered in the SCP-CD with borehole emplacement of the waste package, but for drift emplacement the role of packing and backfill are under consideration.

(5) The backfill material would be used to fill the repository drift after waste packages are emplaced. The backfill diverts water away from the waste package and raises the temperature of the container because of the relatively poor thermal conductivity of the proposed materials. Use of backfill has long been a controversial topic for the Yucca Mountain repository and waste package design. However, the Project is currently reconsidering the use of backfill, and possibly combining some of the functions of the backfill and packing materials. Often associated with the backfill material is the invert material. The invert is the material that will be used to fill the bottom of the drift to create a level surface on which the waste package will be emplaced. The invert is likely to be made of a cementitious material, possibly with an additive to provide a longer service life. The waste package itself will likely be placed on some kind of pedestal for support. Details of the waste package support are currently under development.

(6) The non-metallic barrier materials are proposed as an alternative to an all-metallic waste package container. If metals cannot be demonstrated to meet the containment objectives, then a combination metal/non-metallic waste package may be needed to combine the fracture toughness properties of the metals with the chemical resistance of the non-metal. Ceramic materials are the major non-metallic candidate materials. The non-metallic component could be a separate "stand-alone" barrier or it could be applied as a coating onto a metal container.

Two metallic waste package "container-type" components that are outside the discussion of candidate materials are the multi-purpose canister (MPC) for spent nuclear fuel and the pour canister for the glass waste form. Material evaluations for these components are performed by other parts of the DOE complex, outside the purview of the Yucca Mountain Project. However, the presence of these components in the waste package requires consideration of how they can affect the performance of the disposal container, and perhaps more importantly how the materials used in the disposal container and other engineered barrier materials can affect the performance of the MPC and the pour canister for glass. Pour canisters for glass waste forms will be made of Type 304L stainless steel (UNS S30403). The initial procurement of MPCs will be made from either a low-carbon austenitic stainless steel or a stabilized grade of austenitic stainless steel. It is possible that future MPCs might be made of one of the candidate materials for the disposal container, so that the MPC will be truly tri-functional (storage, transportation, and disposal.).

The terminology is sometimes confusing between MPC for multi-purpose canister and our multiple barrier waste package container, which we use synonymously with disposal container. The MPC will be emplaced around spent fuel assemblies at the reactor site. The spent fuel assemblies will be partitioned from one another by the "basket" material. The first order of MPCs, due in 1998, will be made of stainless steel. The multiple barrier waste package (or disposal container) will be emplaced around the MPCs (containing the spent fuel assemblies and the basket material) at the repository site. The multiple barrier waste package will be fabricated from at least two of the materials discussed in this report under metallic barriers. As discussed in this report, one of these barriers could be made of a non-metallic material if conditions warrant it. The concept is one of a "can inside a can inside a can" (as an example, a stainless steel MPC inside a corrosion resistant inner barrier inside a corrosion allowance outer barrier). Analogously, for the vitrified waste packages, multiple stainless steel pour canisters will be surrounded by a corrosion resistant inner barrier, surrounded in turn by a corrosion allowance outer barrier, the last two barriers comprising the multiple barrier waste package.

\section{Metallic Barriers (WBS 1.2.2.5.1)}

During a project workshop on waste package materials, held in May 1994 in Pleasanton, CA, a number of candidate materials were identified. The materials were grouped according to their expected performance, and three groups of materials were identified for waste package containers. The groups are (1) corrosion resistant materials, (2) corrosion allowance materials, and (3) intermediate materials. Corrosion resistant materials possess good to excellent general corrosion resistance in a wide range of environments. If corrosion resistant materials fail, it is most likely by a localized 
corrosion mode (e.g. pitting, crevice, intergranular) or environmentally accelerated cracking (e.g. stress corrosion, hydrogen embrittlement). Microbiologically influenced corrosion (MIC) can drastically influence localized corrosion and environmentally accelerated corrosion because of alteration in the chemical properties of the environments. Corrosion allowance materials are expected to show measurable general corrosion in nearly all environments. MIC also affects the rate of general corrosion because of the environmental changes. However, under some circumstances, corrosion allowance materials can undergo localized corrosion and environmentally accelerated cracking. A third group of materials was identified during the workshop - an intermediate category of moderately corrosion resistant materials, showing properties between the two other groups. As a practical matter, corrosion allowance materials are used in relatively thick sections because the added thickness (and cost) allows for a calculated wastage of material due to corrosion and thus extends the service lifetime. On the other hand, corrosion resistant materials are used in relatively thin sections because, above the thickness required for mechanical stability, added thickness does not usually improve service lifetime, but only increases cost. The approximate thicknesses of the barriers envisioned in the current Controlled Design Assumptions are $2 \mathrm{~cm}$ for the inner corrosion resistant barrier and $10 \mathrm{~cm}$ for the outer corrosion allowance material. If one of the intermediate materials were used for the latter, it would likely be used in a thickness somewhat less than $10 \mathrm{~cm}$.

Grouping of materials is based on our collective previous experience and knowledge of the materials selection process in previous applications, usually not concerned with nuclear waste disposal. This knowledge is supported by documentation of materials performance, such as that collected in the degradation mode surveys [2-5]. The purpose of these surveys was to compile the large body of previously published information on material performance and to apply this information to our expectations of conditions at Yucca Mountain. The recommendations of materials for the SCP-CD of the waste package, completed in 1991, was also a logical place to begin the effort to identify materials for advanced waste package designs [6].

Two very important factors in determining the performance of candidate materials are the thermal characteristics of the environment and at what projected point in time water can contact the metal surface. The current waste package design is considering a wide range of areal thermal loads and is focusing on two ranges of thermal loads [7]. In one range, corresponding to the "high thermal load", the; surface temperature of the disposal container will not go below $100^{\circ} \mathrm{C}$ for more than a thousand years after emplacement, which will be after the statutory containment period. In the other range, corresponding to the "low thermal load", the surface temperature will always below $100^{\circ} \mathrm{C}$ after emplacement. The possibility of water contact on the container surface therefore depends on (A) the projected time-temperature profiles to attain less than the boiling point isotherm, and (B) the geological and hydrological conditions amenable to transport of water to the vicinity of the waste package once the temperature has cooled to below boiling.

The two ranges of thermal loads for configuration the repository create two different material responses. In the case of a high thermal load, a corrosion allowance outer barrier will slowly oxidize and then corrode slowly or moderately (the rate depending on the water contact and water chemistry) as the temperature descends below the boiling point and water enters the vicinity of the package. As the outer barrier corrodes, it may galvanically protect the inner more corrosion resistant barrier, depending on the combination of marerials considered and if they are in sufficient close contact with one another. When the outer barrier is wasted away, the iiner barrier must "stand on its own", hence a high requirement on corrosion resistance. However, by this elapsed time, many of the fission products in the waste will have decayed and the consequences of release through a breached container are less severe. For a "low thermal load" scenario, the entry of water may occur sooner; hence the reliance on more corrosion resistant materials for both the inner and outer barriers. It is important to note that microbes also need an aqueous environment for their propagation, and the low thermal load scenario means that damage caused by MIC must be appropriately considered in the material selection and testing effort. Although aqueous conditions must be addressed for both thermal load ranges, the possibility of water entry earlier in the containment period means that the susceptibility of various forms of corrosion has a much stronger bearing on materials selection to meet the containment objectives than if aqueous conditions have to be considered at a much later time.

An important aim of the corrosion testing and physical evaluation activities is to guide the design effort in the choice of materials for each barrier. These activities are described in the Scientific Investigation Plan (SIP) for the Metallic Barriers task [8]. While the current waste package design effort emphasizes the corrosion resistant material as the inner barrier, surrounded by a thick corrosion allowance barrier [9], it is possible that the testing activities and accompanying analyses might suggest another configuration of the barriers. This point is also considered in the discussion of non- 
metallic barriers. It is also possible that some "tailoring" of waste package containers could be effected; for example using different materials for packages at the periphery of the repository as opposed to those in the center, or using to use different materials for reprocessed glass waste packages as opposed to spent fuel waste packages. However, using different materials for some waste packages has a serious disadvantage. Separate processing lines would be needed at the repository surface facility to handle different construction materials. This would be a costly operation requiring strong justification for using different materials for different types of waste packages.

The candidate materials are listed in the Table 1. As far as possible, the Unified Numbering System (UNS) identifier is used, and this is cross-referenced to the American Society for Testing and Materials (ASTM) designation [10]. It is important to point out that the ASTM designation is accorded by product form, and so plate material (used, for example, to fabricate the container shell) would have a different designation from a forging (used, for example, to fabricate the container top or bottom). Also, ASTM designations often apply to several materials of different compositions, hence the specification of grade in certain instances. For the candidate materials used in wrought form, the ASTM plate designation was used in Table 1. ASTM designations indicate the industry acceptance of the material, hence these materials fulfill the regulatory requirement of being currently available technology. The UNS designation is based on alloy composition; because of the importance of alloy composition in determining performance, the UNS designation is preferred as the primary identification of candidate materials.

\section{Corrosion Resistant Candidate Materials}

Multiple candidates are presented as corrosion resistant materials that could be used as an inner barrier in a multiple barrier waste package container. The rationale for their inclusion is briefly discussed below. As shown in the accompanying table, the corrosion resistant materials divide themselves into three groups with at least a pair of materials in each group.

(1) Nickel-rich stainless alloys. These materials can be viewed as "super stainless steels", where the increased alloy content, especially the nickel content, confers additional corrosion resistance. The candidate materials are $\mathrm{Ni}-\mathrm{Fe}-\mathrm{Cr}-$ Mo alloys with additional alloying, such as $\mathrm{Cu}$ and $\mathrm{Ti}$, for imparting additional resistance to specific forms of corrosion. UNS N08825 or Alloy 825 or Incoloy 825 (its original trademarked name), which has long been one of the standard alloys in this group, was originally developed for equipment to handle sulfuric acid. It is also virtually immune to chloride-induced stress corrosion cracking even in very concentrated chlorides. However, the alloy can suffer pitting and crevice attack under some combinations of low $\mathrm{pH}$ and high chloride conditions, because of the relatively low $3 \%$ molybdenum content. For this reason, the very similar higher Mo (6\%) alloy UNS N08221 was developed by the industry. In making up the candidate list, during the May 1994 workshop, this alloy was "paired" with Alloy 825, since these materials would share similar properties and expected corrosion behaviors except as noted above. Since the workshop, contact with the nickel industry revealed that the UNS N08221 alloy, which most closely approximates Alloy 825, is not currently being manufactured. Other alloys, such as Alloy G-30 (UNS N06030) and Alloy G-3 (UNS N06985), are therefore considered in its place, since they have around $6 \% \mathrm{Mo}$ and a Ni-Cr-Fe content not too distant from that of Alloy 825 . As will be discussed in the next section, the additional Mo content confers improved corrosion resistance but also increases some phase stability concerns.

(2) Nickel-base alloys. These materials can be viewed as yet another extension of the previous group where $\mathrm{Ni}$ has largely replaced $\mathrm{Fe}$ in the composition. These are the Ni-Cr-Mo alloys. These alloys typically contain only a few per cent $\mathrm{Fe}$ in order to accommodate recycling scrap material of mixed alloys. These alloys were developed because of their superior corrosion resistance to a wide variety of chemical media, and these alloys are used extensively to handle various acids and other aggressive environments. They also appear to be immune from microbiologically influenced corrosion (MIC) [11]. The proposed pair is Alloy $\mathrm{C}-22$, which is a nickel base alloy containing large additions of $\mathrm{Cr}$ and $\mathrm{Mo}$, and a related Alloy $\mathrm{C}-4$. These alloys are often called by their original trademarked names Hastelloy $\mathrm{C}-22$ and Hastelloy C-4. Between the two alloys, C-22 is used more frequently in the USA; C-4 is used more often in Europe. One disadvantage with the high $\mathrm{Cr}-\mathrm{Mo}$ content of these alloys is the possibility of forming sigma, chi, and other brittle phases during alloy processing and welding. Both alloys are highly corrosion resistant, but C-22 appears to be the more resistant in the most highly aggressive conditions, while $\mathrm{C}-4$ appears to be more weldable (by arc 
processes) in the sense that fewer potentially brittle phases form. Thus, for applications in fabricating nuclear waste containers, there are a number of trade-oif factors between Alloys $\mathrm{C}-4$ and $\mathrm{C}-22$, which need additional evaluation during the corrosion testing, phase stability, and weld process development activities planned for this Project.

(3) Titanium. The pair of materials are Gracle 12 titanium, which is a dilute titanium-basealloy containing small additions of $\mathrm{Ni}$ and $\mathrm{Mo}$, and a related Grade 16 titanium, which contains small noble metal additions. Titanium has outstanding corrosion resistance in very ligh chloride media and under very low $\mathrm{pH}$ conditions, which are characterisitic chemical conditions found in creviced regions. Titanium is also believed to be immune to MIC. Grade $12 \mathrm{Ti}$ is widely used in the chemical industry and in marine applications where chloride is highly concentrated (e.g. desalination plants); Grade 16 is a new irdustry development, making use of a small noble metal addition (palladium) that confers additional corrosion resistan:e [12]. Grade 16 offers even greater crevice corrosion resistance than Grade 12 and is entirely single phase, so that it should be less susceptible to hydriding effects. The Canadian AECL nuclear waste program is interested in Grade 16 in their high saline groundwater environment. Differences in the two titanium-base materials need additional evaluation for nuclear waste application.

With respect to ultimately choosing among the candidate corrosion resistant materials, we plan to work closely with industrial groups - particularly the Nickel Development Institute (NiDI) and the Titanium Development Association (TDA). This interaction may reveal additionil candidate materials for consideration. Although these compositional differences may appear small, the nuances in alloy composition are important to the testing activities, and as far as possible, the corrosion testing, and microstructural evaluation of the alloys should initially consider a reasonably wide range of candidate corrosion resistant materials.

\section{Corrosion Allowance Candidate Materials}

The corrosion allowance candidate materials are (1) 1020 carbon steel in wrought form, (2) essentially 1020 carbon steel in cast form, and a (3) $2.25 \mathrm{Cr}-1 \mathrm{Mo}$ alloy steel. The ASTM designations for these materials are given in Table 1. Steels as economic corrosion allowance materials are expected to be satisfactory under dry conditions, such as those expected with a high thermal load repository. Under moist conditions, their performance is marginal, and if the environment is wet and aggressive (high electrolyte or acidic $\mathrm{pH}$ ) the steel will be unsatisfactory even in thick sections. It is expected that under aqueous conditions, the performance of the carbon steels and the alloy steel will be quite similar to one another. Steels are susceptible to MIC, and there are many kinds of microbial species, both aerobic and anaerobic types, that are damaging to steel structures. "The $\mathrm{Cr}$-Mo alloy steel is expected to have a higher oxidation resistance than the plain carbon steels, and this may be a benefit in the higher areal thermal load case or if backfill is used causing a higher surface temperatures on the container for prolonged periods of time. However, fabrication and welding considerations vary among the three candidates in this category, and it is expected that these factors will largely influence which of the three would be selected as a coriosion allowance material for waste containers.

\section{Intermediate or Moderately Corrosion Resistant Candidate Materials}

The May 1994 materials workshop identified a third group of materials, which are referred to as "intermediate" between the corrosion allowance and corrosion resistant groups, because they have some performance characteristics of both. They are (1) Alloy 400, which is sometimes called Monel 400, and (2) CDA 715, which is sometimes called 70/30 copper-nickel. The reason for including thesi materials is that they could function as an alternative to steel under environmental conditions that are too aggressive for steel. For instance, if a low thermal load repository design were used and evaluation of the near-field environment indicated an early entry of water into the vicinity of the waste package, one of these materials could be selected for the outer barrier since they possess good corrosion resistance in water and moist air. These materials are often used under the moderately aggressive conditions of marine applications because they show a great deal of resistance to localized corrosion and stress corrosion, and thus would resist some electrolytic concentration in the environment. Although $\mathrm{Cu} / \mathrm{Ni}$ and $\mathrm{Ni} / \mathrm{Cu}$ alloys are susceptible to $\mathrm{MIC}$ by sulfate reducing bacteria, there a fewer species of microbes causing attack than for carbon steels. As a class of materials, however, $\mathrm{Cu} / \mathrm{Ni}$ and $\mathrm{Ni} / \mathrm{Cu}$ alloys do not possess the high corrosion resistance of the Ni-Cr-Mo alloys or titanium over as wide a range of environments, and they would not be expected to perform well under very aggressive environmental conditions, such as the combination of 
low $\mathrm{pH}$ and high chloride concentrations. However, these alloys possess simple microstructures so that long-term aging and embrittlement phenomena are not likely. It has been suggested that $\mathrm{Cu}$-bearing alloys may be more compatible with the glass waste form than Fe-bearing alloys. Further testing and evaluation of the $\mathrm{Cu} / \mathrm{Ni}$ and $\mathrm{Ni} / \mathrm{Cu}$ alloys is needed to establish the benefits and limitations of these materials in nuclear waste containment.

\section{Basket Materials (WBS 1.2.2.5.2)}

One of the major activities in this WBS element will be the evaluation of candidate materials that will meet the long-term criticality control requirements in the large spent fuel waste packages. The basket material has taken on increased importance in the waste package development activities because of the planned use of large waste packages comprised of several fuel assemblies (12 to $24 \mathrm{PWR}$ assemblies, up to $40 \mathrm{BWR}$ assemblies). Desirable materials properties are high thermal conductivity in the initial containment period, high neutron absorption over the containment and controlled release periods, and long term structural stability. Materials must also be fabricable and compatible with other materials in the waste package. Recently, a scientific investigation plan (SIP) for the basket materials was completed and outlines the work to be performed on this class of materials for the next few years [13]. Because a single material may not meet all of the required and desirable properties, the basket may be made of a composite of materials.

Borated materials, i.e. having additions of elemental boron or boron carbide, meet the neutron absorption requirement. In principle, boron or boron carbide could be added to such structural materials as stainless steel, copper, nickel, aluminum, and so on. However, limitations of solubility in the resulting alloy and potential embrittlement problems must be considered. With many materials, such as $\mathrm{Al}$, the boron will form a boride $\left(\mathrm{AlB}_{2}\right)$, and with the stainless steels these borides can become complex involving the transition metals $(\mathrm{Fe}, \mathrm{Ni}, \mathrm{Cr}, \mathrm{Mn}, \mathrm{Mo})$ and carbon that are present in the stainless steel. Borated aluminum has been produced by either boron or boron carbide additions to the commerical pure $\mathrm{Al}$ (1100 grade) or to the 6000 series alloys. Borated copper is produced by $\mathrm{B}_{4} \mathrm{C}$ additions to $\mathrm{Cu}$. Borated stainless steels have been produced by boron additions to the 304 grade and to other compositions. Typically the borated materials contain $1-4 \% \mathrm{~B}$, depending on the alloy system. The long term corrosion behavior of these basket materials must be considered in case the disposal container is breached. The corrosion behavior will, of course, depend on the environmental conditions that develop closest to the basket material, the matrix material for the basket, and the form and distribution of the boron or boron carbide particles. In many cases the corrosion attack is expected to have a localized characteristic, since the electrochemical potential differences between the matrix metal and the boron-containing particles is likely to be large, and this may promote pitting attack or intergranular attack.

The structure of the borated material is also important. In some cases, the particles are evenly distributed through the matrix; in other cases, a decidedly layered or "sandwich" structure is formed, depending on the process history of the material. Powder metallurgy is used as the primary fabrication for some materials; other are fabricated in conventional wrought products. Still others are composite products, consisting of the borated material clad with or sandwiched in between the non-borated material. Therefore, the microstructural characteristics are expected to play an important role in the performance of the candidate basket materials containing boron as the neutron absorbing element.

A high corrosion resistance of the basket material to a range of environmental conditions is sought. Aqueous conditions are particularly damaging because water is a moderator for neutron activity. Corrosion of the basket materials resulting in extensive wastage or collapse of the partitions around the spent fuel assemblies could result in a critical mass of fissionable material. Specifically, radiolytic effects can create rather oxidizing and aggressive chemical conditions on the basket material surface if moisture or water is also present. Scenarios have been developed in which are formed such species as nitric acid, hydrogen peroxide, formic acid, oxalic acid, and mixtures of these species. Use of aluminum or copper based materials would be readily attacked by these highly aggressive environments. Borated stainless steels may perform somewhat better under these conditions, but there are limitations on what concentrations of aggressive species the stainless steel can endure. Stainless steels also lack the high conductivity of $\mathrm{Al}$ or $\mathrm{Cu}$.

Because corrosion of the matrix material in borated materials or selective leaching of boron from the material can both result in the loss of neutron absorption properties, materials containing other elements with high neutron absorption cross section are under consideration. One of the most promising is hafnium. Hafnium possesses a high neutron cross-section and high corrosion resistance, but is expensive. Commercial zirconium, e.g. grade 702, contains up to $3.5 \%$ Hf (usually 
less), which is residual from the ore. This material would be more economical than pure Hf, but a somewhat higher Hf content may be required. $\mathrm{Zr}$ and $\mathrm{Hf}$ are resistant to many oxidizing, acidic, and other aggressive chemical environments. Compared to $\mathrm{Al}$ and $\mathrm{Cu}, \mathrm{Zr}$ and $\mathrm{Hf}$ are not as good thermal conductors.

Ceramic and other non-metallic are also considered for basket materials because of their expected high degree of chemical stability in aggressive environments. Among the possible candidates are monolithic boron carbide $\left[\mathrm{B}_{4} \mathrm{C}\right]$, a boron carbide aluminum ceramic, and such synthesized minerals as gadolinium-containing monazite (a rare earth phosphate), baddeleyite containing hafrium $\left[\mathrm{ZrO}_{2}-\mathrm{HfO}_{2}\right]$, zircon containing hafnium $\left[(\mathrm{Zr}, \mathrm{Hf}) \mathrm{SiO}_{4}\right]$, and zirconolite containing gadolinium and/or hafnium $\left[(\mathrm{Ca}, \mathrm{Gd})_{1}(\mathrm{Hf}, \mathrm{Zr})_{1}(\mathrm{Ti}, \mathrm{Al})_{2} \mathrm{O}_{7}\right]$. Of course, ceramic materials are less fracture tough and more difficult to fabricate than metals, so that the feasibility of producing them in a suitable form would have to be demonstrated. Ceramic materials are very poor thermal conductors.

It is apparent the above factors need to be weighted to arrive at a number of candidate basket materials for further evaluation. The limited number of materials possessing a high neutron absorption coupled with properties for long-term stability, corrosion resistance, good thermal conductivity, and formability into the desired shape for a basket is very demanding set of requirements for a single material. A composite of materials may fill these requirements, such as a high conductivity metal, like $\mathrm{Al}$, to act as a thermal "shunt" for the shorter term heat transfer need and another more highly corrosion resistant metal or ceramic for the longer term criticality control need. Once the $\mathrm{Al}$ has fulfilled its purpose, its subsequent degradation or destruction must not be detrimental to the long-term structural and criticality control function of the remaining basket material. The compatibility of these different materials is a very important consideration.

\section{Filler Materials (WBS 1.2.2.5.3)}

Future work will identify materials that could be used as internal solid filler materials in spent nuclear fuel waste packages, as opposed to an inert gas filler. Desirable functions include thermal conductivity, neutron absorption and water exclusion for criticality control, modif cation of the environment ( $\mathrm{pH}$ buffer, redox buffer), and prevention of water/oxygen from contacting spent fuel. Metal powders or shot, metal oxide powders or beads, and fusible metals are the types of materials that could be used. Filler materials are design options that could be employed if needed to better demonstrate the criticality control and contrclled release requirements. Because most spent fuel is expected to arrive at the repository already encanistered in the $\mathrm{MPC}$, it is undesirable to open these canisters to insert a filler material unless absolutely necessary. In future specifications of MPC materials, the filler material may be incorporated into the specifications if analysis indicates that these options are necessary.

\section{Packing Materials (WBS 1.2.2.5.4)}

Future work will identify materials that couli be used as external waste packing. Desirable candidates would be materials that could exclude or reduce water contact with the container surface, or materials that could retard certain radionuclides that escaped breached waste package contairers. Packing materials that further modified the waste package environment and therefore reduced corrosion effects on the container may be desirable. Severe disadvantages of packing materials are the low thermal conductivity, which increases surface and internal temperatures, and the possibility that some of the clay materials proposed for packing materials might retain water (rather than repel it) and create a crevice around the container surface. Packing materials are design options that could be employed if needed to better demonstrate compliance with the containment and controlled release requirements. Some of the attributes of the packing material may be combined with those of the backfill material, discussed in the next section.

\section{Backfill Materials (WBS 1.2.2.5.5)}

Future work will identify materials that could be used as backfill. Currently, crushed tuff retained from the repository excavation is proposed as a gravel. The thermal and hydrological properties of the crushed rock remain to be determined. It would be desirable if the backfill could act as a potential capillary barrier to water ingress to the container surface. Any 
incoming water is expected to evaporate on the gravel surface before encountering the container surface. Emplacement of crushed rock as a gravel backfill is expected to raise the container temperature because of the rather low thermal conductivity of the rock. Depending on when the backfill operation is performed, this operation can have a beneficial or detrimental influence on the waste package contents and the waste package container materials. If the backfill installation causes temperatures to rise above about $350^{\circ} \mathrm{C}$ in the interior of the spent fuel waste packages, the condition of the fuel cladding is likely to be seriously degraded, and this has implications on demonstrating controlled release of long-lived radionuclides. Surface temperatures much above $300^{\circ} \mathrm{C}$ on the container can introduce high temperature degradation phenomena, such as enhanced oxidation, creep, and phase instability that would have to be considered. Also, a breach in the container in this period of time (for instance, a weld failure) would produce the possibility of excessive oxidation of spent fuel and release of gaseous or air-borne radionuclides. Still another potentially detrimental effect of backfill is creation of crevices around the waste package and introduction of microbial activity due to the operation of removal, processing, and application of the backfill in very close proximity to the waste package container. The crevice and microbial degradation concerns occur only when aqueous conditions are present - and this a very long time, if ever, following the backfill operation.

Future project work may identify different kinds of materials that could be used as backfill. Mixtures of materials could provide both a backfill function and packing material function. The current working design assumptions do not include backfill, but recognize the need to consider the possibility of using backfill for drift stability or as a capillary barrier. Work is planned to evaluate the backfill option and the materials that could be used.

\section{Non-Metallic Barriers (WBS 1.2.2.5.6)}

Non-metallic materials, particularly oxide ceramics, have been considered as highly chemically resistant materials that could be used as one of the barriers in a multiple barrier design if the predicted performance of the metallic barriers does not demonstrate adequate containment. One such scenario is an extreme case of MIC where the performance of all the candidate metallic materials is inadequate. Another scenario is that the performance of even the most corrosion resistant material could not be demonstrated because of our inability to convincingly model localized corrosion or stress corrosion phenomena. Ceramic materials, compared to metallic barriers, offer chemical "inertness" in many instances, but ceramics as a class of materials do not possess nearly as much fracture toughness as metals. A composite waste package design using both metallic barriers and non-metallic barriers may, therefore, provide the appropriate combination of mechanical and chemical properties to assure long term containment.

In addition to fragility, the fabrication and joining or sealing of a ceramic barrier are major issues in candidate material and process selection. As a composite barrier, the ceramic may be a free standing separate barrier or it may be applied as a thick internal or external coating. The choice of candidate materials is dependent on whether the ceramic would be used as a free standing barrier or as a coating.

A free standing barrier could be produced by stacking rings of alumina to produce a cylindrical shell. Alumina ceramics can be produced in large-diameter rings by current technology. Joining of the rings could be accomplished by diffusion bonding or by brazing alloys compatible with the ceramic. Cementitious materials could also be used for joining. The materials and processes used to fabricate and join them have advantages/disadvantages that would have to be further evaluated.

One particularly promising process is an external ceramic coating applied on a metallic barrier by flame spraying. This configuration has the advantage of not requiring a sealing operation. Issues with applications of coating include the rate of deposition (since rather thick coatings are desired) and porosity. Materials that could be flame sprayed are spinel, a magnesium/aluminum oxide, and mullite, an aluminum silicate. Titania based ceramics are another class of materials that offer a high degree of chemical resistance. Internal coatings present more challenges in fabrication. While an empty cylinder could be spray coated, closure of such a coated structure would be difficult.

The choice of non-metallic candidate materials is intimately related to the process used to fabricate them or coat them on a metal surface. A feasibility study on approaches that one might use in making a non-metallic barrier has recently been completed [14]. As work continues in laboratory demonstration of a non-metallic barrier, candidate materials and 
processes for using them will be better specified. Recently, an industry-wide numbering system for ceramic materials has been developed by the American Ceramic Scciety, comparable to the long-established system for identifying metals and alloys. This should standardize ceramic material nomenclature and help to establish these materials as fully accepted engineering materials.

\section{Final Remarks}

This engineered barrier system candidate list will be updated as required by changes in the waste package design or other programmatic elements that influence the selection of materials. Also, as results from the materials testing and performance modeling are obtained, modifications to the candidate list may be necessary. The first version of the Engineering Characterization Report (EMCl) has been prepared [15], and planned updates will provide information on the candidate materials for the various components as results from corrosion testing, physical evaluations, and other analyses becomes available. The EMCR summarizes several of the more detailed references cited above and gives a comprehensive history of the container materials (and other elements of the EBS) effort over the last several years. The EMCR gives an account of the May 1994 materials workshop, during which many of the candidate materials were identified. As indicated at various points in the above discussion, evolution of waste package and repository designs will occur, possibly resulting in some changes in strategy on meeting the different requirements placed on the engineered barriers. As explained in the text, use of sorne of the components is a design option that may be exercised if needed. These include the backfill with or without packing. Also, the role of the "basket materials" is expected to evolve. The requirements for the "basket material" are quite demanding for a single material, and a composite material approach is likely needed to meet all these requirements. The possible incorporation of a filler material to further provide criticality control in spent nuclear fuel waste packages will also need to be addressed.

A detailed list of candidate materials has been developed for the Metallic Barriers WBS element; corrosion studies and other evaluations on the candidate materials are underway and a significant effort is planned in this area for the next several years. Although a number of materials have been suggested for the basket material and for the non-metallic barrier material efforts, some of these materials may not be feasible because of high costs and/or difficulty in fabricating to suitable product forms. Thus, the candidate lists for these functions are likely to undergo substantial revision as the candidate materials are more fully evaluated and tested. More detailed candidate lists for the other EBS components, especially packing and filler materials, await sufficient initial scoping work before such well-defined lists can be developed for these barriers.

This list of candidate materials was prepared and organized by R. D. McCright, LLNL, Technical Area Leader for Engineered Barrier Materials, with the consultation of Willis Clarke, Edward Dalder, Richard Van Konynenburg of LLNL and of David Stahl of the M\&O/B\&W Fuels Co. The candidate list follows from the recommendations made by participants at the YMP Materials Workshop in May 1994 with subsequent modifications noted in the above discussion. 


\section{References}

[1] Controlled Design Assumptions Document, B00000000-01717-4600-00032 Rev. 1, TRW Environmental Safety Systems (1995)

[2] J. C. Farmer et al, Survey of Degradation Modes of Candidate Materials for High-Level Radioactive Waste Disposal Containers, Volumes 1-8, LLNL UCID-21362 (1988)

[3] G. E. Gdowski, Survey of Degradation Modes of Four Nickel-Chromium-Molybdenum Alloys, LLNL UCRL-ID108330 (1991)

[4] D. W. Vinson, W. M. Nutt, and D. B. Bullen, Survey of the Degradation Modes of Candidate Materials for HighLevel Radioactive Waste Disposal Containers - Iron-Base, Corrosion Allowance Materials, UCRL-CR-120464, (1995)

[5] G. E. Gdowski, Survey of Degradation Modes for Titanium, LLNL UCRL-ID 121191 (1995)

[6] R. A. Van Konynenburg, W. G. Halsey, R. D. McCright, W. L. Clarke, G. E. Gdowski, Selection of Candidate Container Materials for the Conceptual Waste Package Design for a Potential High Level Waste Repository at Yucca Mountain, LLNL UCRL-ID-112058, (1993)

[7] D. Stahl, J. K. McCoy, and R. D. McCright, Impact of Thermal Loading on Waste Package Material Performance, in the Proceedings of the Symposium for the Scientific Basis for Nuclear Waste Management XV, Materials Research Society (1994)

[8] Scientific Investigation Plan - Metallic Barriers Task, WBS 1.2.2.5.1, SIP CM-01, revision 2, Lawrence Livermore National Laboratory (1994)

[9] Initial Summary Report for Repository/Waste Package Advanced Conceptual Design Volume 1, Document No. B00000000-01717-5705-00015 Rev.00, TRW Environmental Safety Systems (1994)

[10] Metals and Alloys in the Unified Numbering System, Fourth Edition, Society of Automotive Engineers, SAE HS J1086 APR 86, ASTM DS-56 C, Warrendale PA (1986)

[11] G. Geesey, A Review of the Potential for Microbially Influence Corrosion of High-Level Nuclear Waste Containers, Center for Nuclear Waste Regulatory Analyses, CNWRA 93-014, (1993)

[12] R. W. Schutz and M. Xiao, Optimized Lean-Pd Titanium Alloys for Aggressive Reducing Acid and Halide Service Environments, Proceedings of the 12th International Corrosion Congress, National Association of Corrosion Engineers (1993)

[13] Scientific Investigation Plan - Basket Materials Task, WBS 1.2.2.5.2, SIP CM-02, revision 0, Lawrence Livermore National Laboratory (1995)

[14] K. Wilfinger, Ceramic Package Fabrication for YMP Nuclear Waste Disposal, LLNL UCRL-ID-118660 (1995)

[15] R. A. Van Konynenburg, R. D. McCright, A. K. Roy, and D. A. Jones, Engineered Materials Characterization Report for the Yucca Mountain Site Characterization Project, volumes 1-3, LLNL UCRL-ID 119564 (1994) 
Table 1

\section{CANDIDATE MATERIALS FOR MULTI-BARRIER CONTAINERS}

\section{CORROSION RESISTANT MATERIALS}

\section{UNS Number \\ Common or Commercial Name}

\section{Nickel-rich Stainless Alloys (Ni-Cr-Fe-Mo Alloys)}

N08825 Alloy 825, Incoloy 825

N08221*

Alloy 825hMo, NiCrFe 4221

B 424 (plate)

B 424 (plate)

\section{Nominal Composition}

Ni 38.0-46.0; Cr 19.5-23.5; Mo 2.5-3.5; Fe balance; $\mathrm{Cu} 1.5-3.0 ; \mathrm{Ti}$ 0.6-1.2; Mn 1.0 max; C 0.05 max; Si 0.5 max; S 0.03 max; Al 0.2 $\max$

Ni 39.0-46.0; Cr 20.0-22.0; Mo 5.0-6.5; Fe balance; Cu 1.5-3.0; Ti 0.6-1.0; Mn 1.0 max; C 0.025 max; Si 0.5 max; S 0.03 max; Al 0.2 $\max$

\section{Nickel-base Alloys (Ni-Cr-Mo Alloys)}

N06022 Alloy C-22, Hastelloy C-22

B 575 (plate)

Ni balance; $\mathrm{Cr}$ 20.0-22.0; Mo 12.5-14.5; Fe 2.0-6.0; W 2.5-3.5; Co 2.5 $\max$; Mn 0.5 max; C 0.015 max; Si 0.08 max; V 0.35 max; S 0.02 $\max ; \mathbf{P} 0.02 \max$

N06455

Alloy C-4, Hästelloy C-4

B 575 (plate)

Ni balance; Cr 14.0-18.0; Mo 14.0-17.0; Fe 3.0 max; Co 2.0 max; Mn 1.0 max; C 0.015 max; Si 0.08 max; Ti 0.7 max; S 0.03 max; P 0.04 $\max$
Ti-Grade 12

Ti-Grade 16
B 265 Grade 12 (plate)

none to date
Ni 0.6-0.9; Mo 0.2-0.4; N 0.03 max; C 0.08 max; H 0.015 max; Fe 0.3 max; 0.25 max; Ti balance

0.05 Pd; Ti balance

*For comparison to (and possible replacement for UNS N08221), the following alloys are considered:

$\begin{array}{lll}\text { N06030 Alloy G-30; Hastelloy G-30 B } 582 \text { (plate) } & \text { Nat }\end{array}$

N06985
Alloy G-3, Hastelloy G-3

B 582 (plate)
Ni balance; $\mathrm{Cr}$ 28.0-31.5; Mo 4.0-6.0; Fe 13.0-17.0; W 1.5-4.0; Co 5.0 $\max$; $\mathrm{Cu} 1.0-2.4$; Nb+Ta 0.3-1.5; Mn $1.5 \max$; $0.03 \mathrm{max}$; Si 0.8 $\max$ S 0.02 max; P $0.04 \max$

Ni balance; Cr 21.0-3.5; Mo 6.0-8.0; Fe 18.0-21.0; W 1.5 max; Co 5.0 $\max$; Cu 1.5-2.5; Nb+Ta 0.50 max; Mn 1.0 max; C 0.015 max; Si 1.0 $\max$; 0.03 max; P 0.04 max 
Table 1 (continued)

\section{CANDIDATE MATERIALS FOR MULTI-BARRIER CONTAINERS}

\section{CORROSION ALLOWANCE MATERIALS}

\section{UNS Number Common or Commercial Name}

\section{Carbon and Alloy Steels}

G10200

1020 Carbon Steel

Centrifugally Cast Steel

K21590

$21 / 4 \mathrm{Cr}-1$ Mo Alloy Steel

\section{ASTM Number}

Nominal Composition

$\begin{array}{llll}\text { J02501 Centrifugally Cast Steel } & \text { A } 27 \text { (Grade 70-40) } & \begin{array}{l}\text { C } 0.25 \text { max; Mn 1.20 max; P 0.50 max; S 0.060 max; Si 0.80 max; Fe } \\ \text { remainder }\end{array} \\ \text { K21590 } & & \text { A } 387 \text { (Grade 22) } & \begin{array}{l}\text { C 0.15 max; Mn 0.3-0.6; P 0.035 max; S 0.035 max; Si 0.5 max; Cr } \\ \text { 21/4 Cr - 1 Mo Alloy Steel }\end{array} \\ \end{array}$

A 516 (Grade 55)

MODERATELTY CORROSION RESISTANT or "INTERMEDIATE" MATERIALS

(performance between corrosion allowance and corrosion resistant)

\section{Copper and Nickel Alloys}

N04400

C71500
Alloy 400 , Monel 400

70-30 Copper Nickel,CDA 715
B 127 (plate)

B 171 (plate)
Ni $63.0 \mathrm{~min} ; \mathrm{Cu} 28.0-34.0 ; \mathrm{Fe} 2.5 \mathrm{max} ; \mathrm{Mn} 2.0 \mathrm{max} ; \mathrm{C} 0.03 \mathrm{max} ; \mathrm{Si}$ 0.5 max; Si $0.5 \max ; \mathrm{S} 0.024 \max$

Ni 29.0-33.0; Cu balance; Mn 1.0 max; $\mathrm{Pb} 0.02 \max ; \mathrm{Fe} 0.4-1.0 ; \mathrm{Zn}$ 0.5 max; C 0.05 max; P 0.02 max; S 0.02 max 